Equally, how will poor performers be encouraged to do better? The market may be an imperfect mechanism for matching performance and resource allocation, but it has undoubtedly acted as a powerful force for change-much of it positive. Labour correctly criticises the high transaction costs in the market and claims that its own policies would offer a better way of improving efficiency. If this claim is to carry conviction it must acknowledge the part that contestability can play in the NHS. This involves not the market testing of health sevices but the ability of commissioning authorities to use alternative providers if they fail to deliver improvements in performance through management mechanisms. Put another way, the threat of competition will provide the incentive to change behaviour, and this will be achieved without incurring high transaction costs.

The second issue that must be clarified is the statutory position of revamped NHS trusts. Experience of making the current reforms work after 1991 showed that the distinction between commissioning and providing services became real only when directly managed units achieved trust status. In particular, this enabled health authorities to concentrate on planning and needs assessment and to avoid being dominated by providers. Labour should make a clear commitment to maintain the statutory separation of commissioning authorities and providers. Debate could then focus on the detail of how providers should be organised, drawing on experience from countries such as Canada and the Netherlands, where the management of hospitals is separated from responsibility for paying for health care.
This is closely linked to the third issue-namely, the way in which the commissioning function itself is organised. Labour favours moving towards a system of either direct election or the integration of commissioning with local government. Both options raise fundamental questions not only about how health services would be funded under these arrangements but also the very principle of a national health service. To make these points is not to argue against greater democratic control of the NHS locally but rather to suggest that thought needs to be given to the wider implications.

However these questions are resolved, one thing is certain: the election of a Labour government would herald further organisational change and a period of continuing instability. The silver lining is that the changes propsed are less radical than once seemed likely, and it will be three years before any of Labour's proposals could come into effect. In that period there is an opportunity not only to refine the details of these proposals but also to test their plausibility. Given the direction of change in Labour's thinking and the fact that the current reforms will by then be even more firmly embedded, almost anything is possible. Let the debate begin.

CHRIS HAM Director

Health Services Management Centre,

University of Birmingham,

Birmingham B15 2RT

1 Health 2000. The health and wealth of the nation in the 21st century. London: Labour Party, 1994.

\section{Generalists in medicine}

\section{General practice is medicine with a human face}

Stuart Handysides's series of articles on enriching careers in general practice (the sixth and last of which is published today (p 513)) has amassed many facts and useful opinions about the state of general practice today. ${ }^{1-6}$ The accelerating pace of change makes the beginning of 1994 a good time to take stock.

Handysides correctly identifies the current importance of morale, career development, inevitable change, partnerships, teamwork, and management in general practice. The question we must answer is, how can we sustain the challenge and privilege of being personal doctors in the front line of a cash limited health service when more and more is being asked of us by professional bodies, the government, and patients? We offer six approaches that seem both theoretically sound and practical in aiding enjoyment of ordinary NHS general practice.

Firstly, we think and practise as "generalists," a term that linguistically and professionally balances "specialists" and that describes most closely the core of our job as doctors. Relating to the whole person and all parts of the body and mind is intellectually fascinating but emotionally demanding. It means getting to know patients as people, including their families ${ }^{7}$ and homes, ${ }^{8}$ and analysing how psyche and soma interact. This offers an opportunity for research that is not available to specialist medicine.

Secondly, we believe that the future lies with multiprofessional teams, including practice managers, practice and community nurses, health visitors, midwives, physiotherapists, counsellors, and computer staff as they can share skills, spread work, and support each other.
Thirdly, patients consult NHS general practitioners on average five times a year, ${ }^{7}$ and in many practices they average another annual consultation with practice nurses. A family of four can therefore expect to consult their general practitioner more than 200 times over the average of 11 years that patients are registered with a single practice. The organisational challenge is to focus all these contacts for the patients' benefit. We believe that continuity for both patients and their doctors is currently undervalued-it takes years to begin to understand patients fully as people. In our partnership we therefore encourage patients to see and get to know the same doctor as far as possible.

Personal lists ${ }^{8}$ are therefore critical for continuity, and even with holidays, half days, and rotas it is possible to average two consultations a year per person. Mutual understanding and therapeutic relationships can then slowly build up. ${ }^{9}$ Such regular, long term contact between patients and their family doctors generates a wealth of information about physical, psychological, and social aspects of health. The fourth issue is therefore computer recording. It takes time to enter information but little time to recall it

Desk top, networked microcomputers are the mechanical slaves that general practice needs to systematise its base for research, teaching, and clinical care. Computerised summaries, warnings about drug interactions, and search and recall procedures take much of the drudgery out of doctoring and are beginning to produce new levels of quality and efficiency leading to new forms of job satisfaction. We call such up to date computerised information about lifestyle, 
current problems, risk factors, and chronic diseases "living epidemiology" and see it as the key to assessing the health needs of small populations. Just as the discovery of anaesthetics in the nineteenth century allowed surgeons to develop their skills so in this century microcomputers are allowing general practitioners to organise and analyse their information and so develop the discipline of general practice.

Computerised audits comparing the care provided by different partners in a practice are now possible. The comparisons are private and internal to the practice, are highly educational, and promote personal professional development by highlighting the strengths and weaknesses of all the doctors.

The Royal College of General Practitioners' fellowship by assessment offers a similar external goal and reward. ${ }^{11}$ By making personal relationships progressive and by making practice data progressively fuller and more interesting a logical career development emerges for the medical generalist within a group practice and a community.

Finally, as Handysides writes, general practice is a human service. The Royal College's motto, cum scientia caritas (compassion with science), well describes the two legs on which our subject stands. Generalists always have been and always will be concerned with whole person medicine, human problems, and human values.

DENIS PEREIRA GRAY Professor of general practice RUSSELL STEELE

Research fellow

KIERAN SWEENEY

Research fellow

PHILIP EVANS

Research fellow

Institute of General Practice,

Postgraduate Medical School,

University of Exeter, Exeter EX2 5DW

\footnotetext{
1 Handysides S. Morale in general practice: is change the problem or the solution. BMF 1994;308: $32-4$.

2 Handysides S. Building morale through personal development. BMf 1994;308:114-6.

3 Handysides S. Building an efficient and healthy practice. BMJ 1994;308:179-82.

4 Handysides S. A career structure for general practice. $B M \mathcal{F} 1994 ; 308: 253-6$.

5 Handysides S. Could the right contract improve morale? $B M \mathcal{F} 1994 ; 308: 455-8$.

6 Handysides $S$. Could the right contract improve morale? $B M 7$ 1994;308:455

7 Huygen FJA. Family medicine. In: The medical life history of families. Nijmegen: Dekker and van de Vegt, 1978. (Republished: London: RCGP, 1990.)

Pereira Gray DJ. Feeling at home. James Mackenzie lecture 1977. 7 R Coll Gen Pract 1978;28:6-17.

9 Pereira Gray DJ. Feeling at home. James Mackenzie lecture 1977. F R Coll Gen Pract 1978;28:6-17. 1991:

10 Pereira Gray DJ. The key to personal care. 7 R Coll Gen Pract 1979;29:666-78.

11 Royal College of General Practitioners. Fellowship by assessment. London: RCGP, 1990. (Occasional paper 50.)
}

\section{Community hospitals in the new NHS}

\section{Have a role but they will have to compete}

The future of community hospitals has always been uncertain within the National Health Service despite widespread support for them, particularly from general practitioners. ${ }^{1}$ Government policies have successively threatened, promoted, and ignored community hospitals, but the number of hospitals has grown over the past two decades. What role do they have now that hospital care is being redefined, and how might they fare in the NHS internal market?

In the 1960s the development of district general hospitals threatened the existence of many of these small hospitals, but in 1974 the Department of Health issued a paper setting out its vision for community hospitals ${ }^{2}$-and that view has not yet been formally superseded. This document suggested that community hospitals were needed to provide medical and nursing care, including outpatient, day patient, and inpatient care, for people who do not need the specialised facilities of district general hospitals and cannot be properly cared for at home or in residential accommodation. General practitioners were expected to provide the day to day care of patients. As a result of this guidance several former cottage hospitals were adapted to meet these new requirements, and in many health districts new community hospitals were developed.

Descriptive studies from England and Wales ${ }^{3}$ and Scotland ${ }^{4}$ have shown that community hospitals have an important part to play in providing certain types of care and suggested that their contribution to the totality of health care should not be underestimated. More recently, the Royal College of General Practitioners and the Association of General Practitioner Community Hospitals produced an authoritative document suggesting that community hospitals were an important resource and met the needs of the local population. ${ }^{5}$ (For example, they can provide inpatient care to many elderly patients by health professionals with whom patients are familiar, within easy reach of family and friends.) EmrysRoberts came to a similar conclusion. ${ }^{6}$

The introduction of NHS reforms (the internal market and general practitioner fundholding) coupled with the rapid increase in the number of places available for care in private sector nursing and residential homes and in the voluntary sector (hospice care) has once again cast doubt on the role and responsibilities of community hospitals.

The previous rewarding relationship that existed between many district general hospitals and their local community hospitals will probably change as they will now be in competition for "business." To generate additional income district general hospitals might well decide to provide a similar kind of care to that given by community hospitals. Alternatively, they might set up satellite services in the community as an extension of their services or even offer inpatient beds to general practitioners.

Added to this uncertainty is the attitude of fundholding general practitioners. Since they hold their own budgets they have the option of admitting their patients to private nursing or residential homes or to voluntary sector hospices instead of community hospitals. The ever expanding private sector in nursing and residential homes represents a real threat to community hospitals.

In a discussion about health needs with general practitioners in South Tees-which has some 150 general practitioners, three community hospitals, and a general practitioner inpatient unit in a long stay hospital-family doctors were asked what role they saw for inpatient beds in community hospitals. Most considered terminal care to be the most important use, but they also wanted beds for care of elderly patients, rehabilitation, respite care, and non-emergency medical care. ${ }^{7}$ This perceived role for community hospitals may be an expression of unmet need in the community. Nevertheless, most of this care could be provided as well in hospices or in private nursing and residential homes, and, despite the views of these general practitioners, a fall in demand for inpatient services in community hospitals is likely. In addition, although many general practitioners claim 